دراسة اقتصادية لمحصول السمسم في مصر

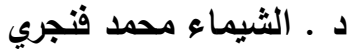 \\ مدرس الاقتصاد الزراعي - كلية الزراعة - جامعة جنوب الوادي

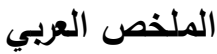

يعتبر محصول السمسم من أهم المحاصيل الزينية فى مصر، حيث تجود زراعته فى الأراضى الصفراء الخفيفة والثقيلة والرملية حيثة

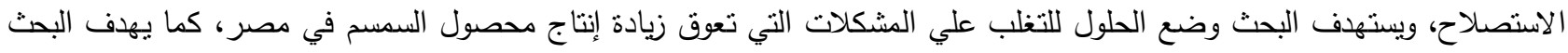
التعرف علي أكثر المتغيرات نأثثرا في استجابة الزراع لزراعة المحصول وقياس كفاءة الإنتاج من خلال دراسة دوال الإنتاج والتكاليف

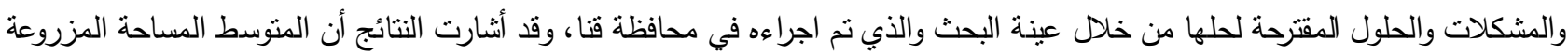

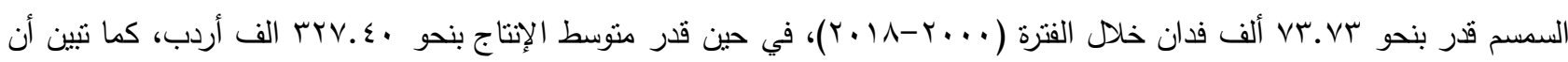

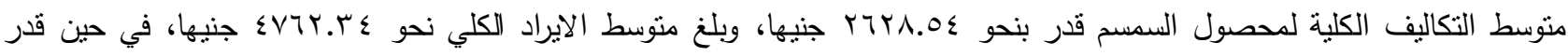

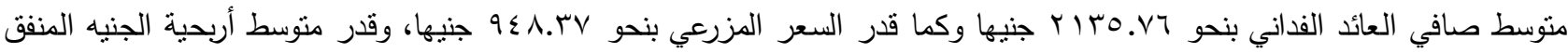

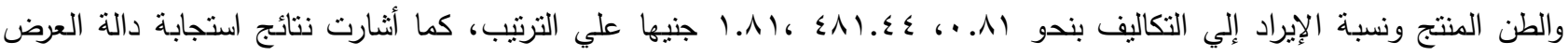
للمحصول أن أهم العوامل الاقتصادية الموثثرة علي المساحة المزروعة السمسم في مصر هي صافي العائد الفداني لكل من محاصيل الفول السوداني، الخيار الصيفي، السمسم، الكوسة الصيفي.

زراعته فى الأراضى الصفراء الخفيفة والثقيلة والرملية حليثة الاستصلاح ، وتتميز قشرة البذرة بارتفاع نسبة الألياف الخام والمواد

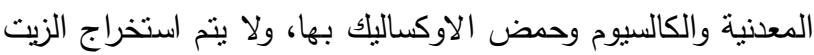

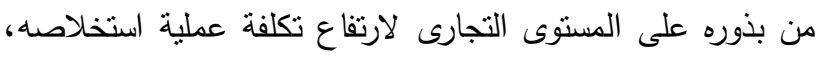

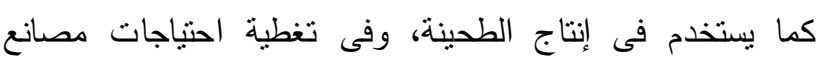

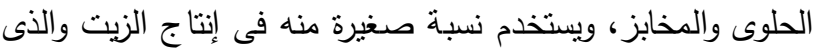

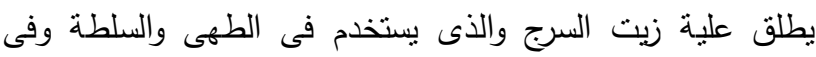

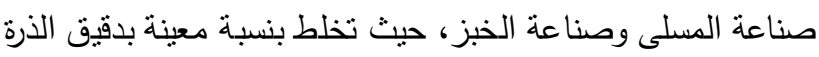

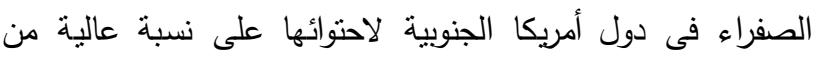

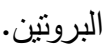

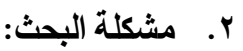

في الاونة الاخيرة لوحظ عزوف المزارعين عن زراعة محصول

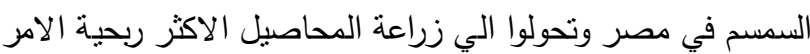
الذي يعزي الي وجود بعض المشكلات الإتناجية والتسويقية لمحصول السمسم التي تواجهة زراعة محصول السمسم وكذلك انخفاض نسبة التهبة

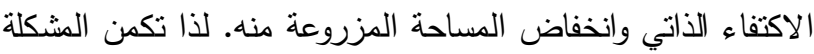

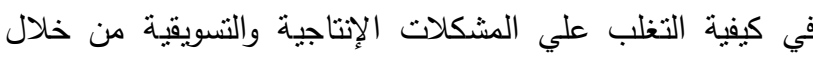
التعرف علي اتجاهات تطور الإنتاج والتكاليف، وتقلير دوال الإنتاج

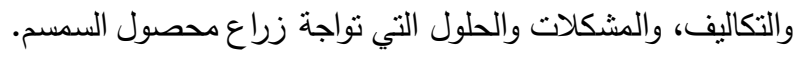

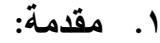

تحتل المحاصيل الزيتية مكانة هامة في المقتصد الزراعي

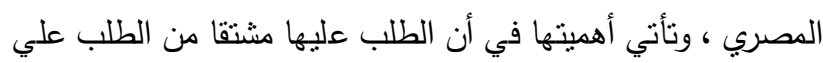
الزيوت النباتية الغذائية والتي نتكل نمطا غذائيا سائدا وأساسيا للمستهلك المصري ، كما تزرع بعض المحاصيل الزينية لاستخدام نواتجها فى إنتاج الزيوت لأغراض ثثائية أو ثلاثية كما فى محاصيل القطن وفول الصويا ودوار الثمس. حيث تنداخل اقتصاديات إنتاج

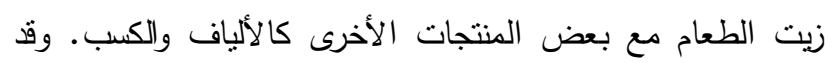
تدخلت الدولة فى تحليد مساحات كل من القطن والفول السودانى

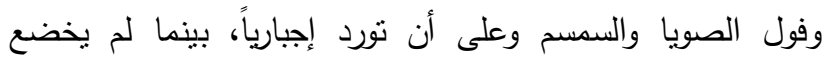
محصول دوار الثمس لهذه القيود. ويتوقف اعنبار أى من هذه

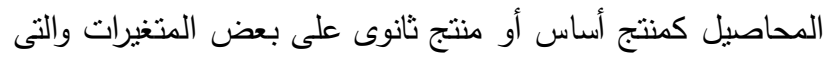

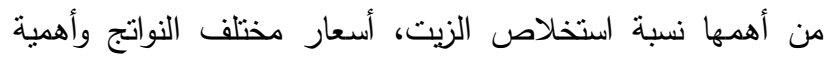

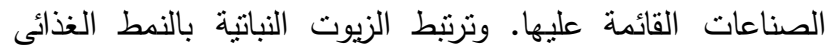
للمستهلك المصرى، لكونها تدخل فى العديد من الأغنية اليومية والتى تتفق مع الذوق المحلى، بالإضافة إلى أنها تنخل كمادة خام

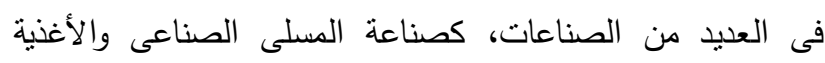
المعلبة، وصناعة الحلوى، كما تستخدم مخلفات تصنيعها فى صناعة الأعلاف المركزة وصناعة الصابون والمنظفات الصناعية. ويعتبر محصول السمسم من أهم المحاصيل الزيتية فى مصر، حيث تجود 
الحصول عليها من الجهات المختلفة منل: وزارة الزراعة واستصلاح

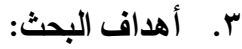

يستهدف البحث اقتراح بعض الحلول للتغلب علي المشكلات الاراضي والجهات التابعة لها ، والجهاز المركزي للتعبئة العامة والاحصاء التي تعوق زيادة إنتاج محصول السمسم في مصر خاصة وأنه من، ومعهد التخطيط القومي ، وبعض المواقع المتخصصة للبيانات ، هذا المحاصيل التي تجود زراعتها في الاراضي التي لانجود فيها زراعليالاضافة الي بعض التي المراجع والدراسات المعنية بموضوع البحث، كما المحاصيل الحقلية الاخري ، كما يهدف البحث إلي التعرف علي أعتمد البحث علي البيانات الاولية التي تم الحصول عليها من استمارة اكثر المتغيرات تأثنرا في استجابة الزراع لزراعة المحصول وقياسلالاسنيان والتي صدمت لهذا الغرض لعينة الدراسة بمحافظة قنا. كفاءة الإنتاج من خلال دراسة دوال الإنتاج والتكاليف والمشكلات تطور مساحة وإنتاجية وإنتاج محصول السمسم فى مصر : والحلول المقترحة لحلها من خلال عينة البحث والذي تم اجراءه في تطور المساحة المزرعة: تبين من الجدول رقم(1) أن متوسط المساحة المزروعة بمحصول

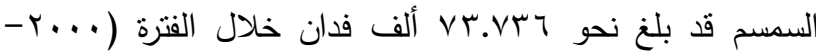

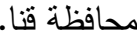

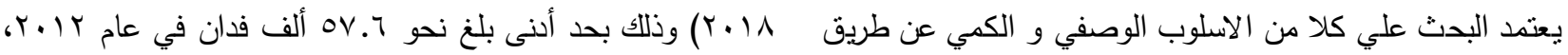

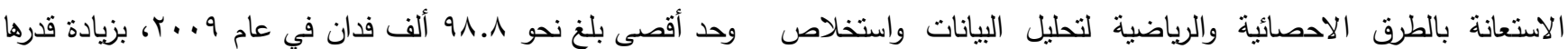

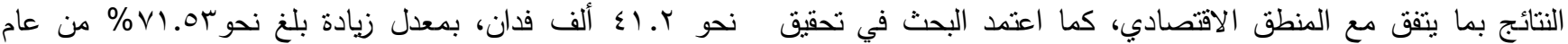
أهدلفه علي كل من البيانات الثانوية المنشورة وغير المنشورة والتي تم ب ا. T، وبتقدير معادلة الاتجاه الزمني العام للمساحة المزروعة

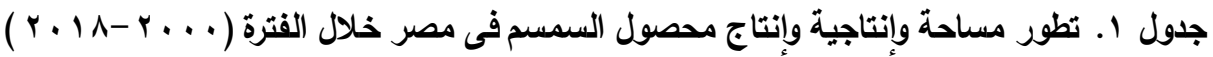

\begin{tabular}{|c|c|c|c|}
\hline الإنتاج الكلى & $\begin{array}{c}\text { إنتاجية الفدان } \\
\text { (أردب) }\end{array}$ & (ألف فدانة) & السنوات \\
\hline T.T.А & E.Y. & VY.E & r... \\
\hline r... & E.Yo & $7 \vee .9$ & $r \ldots l$ \\
\hline$r .7 .0$ & E.ro & VY.I & $r \ldots r$ \\
\hline$r .0 .0$ & $\varepsilon . r V$ & VI.0 & $r . . r$ \\
\hline$r \cdot v . \wedge$ & $\varepsilon . \varepsilon$. & 79.7 & $r \ldots \varepsilon$ \\
\hline r. . & ร.7. & 77.9 & $r \ldots o$ \\
\hline$r \leqslant 0 .$. & క.7. & vo & $r \ldots r$ \\
\hline rol.V & $\varepsilon .7 r$ & Vo.A & $r \ldots v$ \\
\hline$r \cdot V . r$ & $\varepsilon .01$ & $7 V .1$ & $r \ldots \Lambda$ \\
\hline 517.7 & $\varepsilon . r T$ & $9 \wedge . \wedge$ & $r . . q$ \\
\hline r^乏.V & $\varepsilon . \Gamma$ & NV. 9 & $r \cdot 1$. \\
\hline (... & క.7. & VA.r & $r .11$ \\
\hline r... & s.or & ov.7 & $r .1 r$ \\
\hline TVT.T & $\varepsilon .01$ & 09.7 & r. \\
\hline r.rוس & $\varepsilon . \wedge 9$ & ג.זי & $r .1 \leq$ \\
\hline$\varepsilon \ldots 9 V$ & $\varepsilon . V 7$ & NE.r & $r .10$ \\
\hline ו...." & $\varepsilon .79$ & 79.1 & $r .17$ \\
\hline r 70.9. & $\varepsilon .7 r$ & 97.1 & $r .1 \mathrm{~V}$ \\
\hline 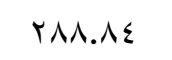 & $0 . . \varepsilon$ & א.דר & $r .11$ \\
\hline rrv.z. & $\varepsilon .01$ & vr.v & المتوسط \\
\hline
\end{tabular}

المصدر : وزارة الزراعة واستصلاح الأراضي، مجلس المحاصيل السكرية ، نشرة التقرير السنوى ، اعداد مختلفة 


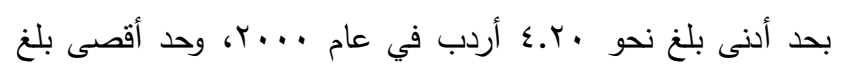

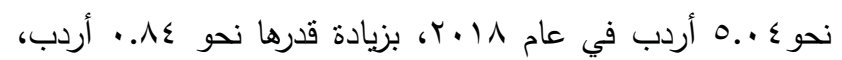

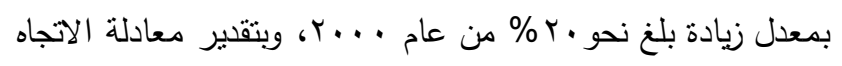

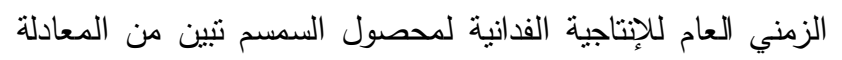

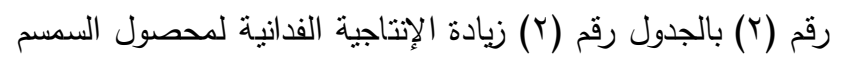

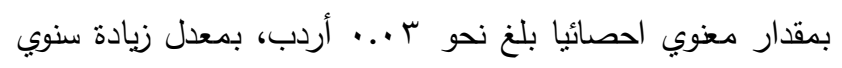

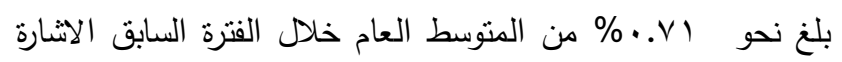

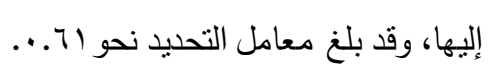

بمحصول السمسم خلال الفترة المشار إليها تيين من المعادلة رقم

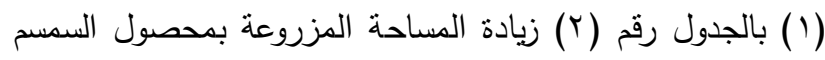

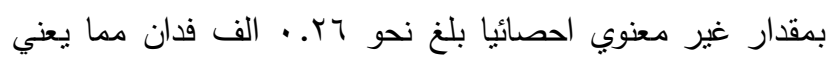

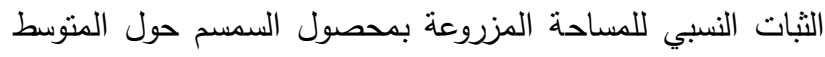
الحسابي خلال الفترة المشار اليها .

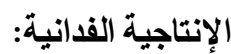
يوضح الجدول رقم(1) أن متوسط الإنتاجية الفدانية لمحصول

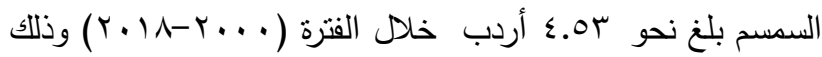

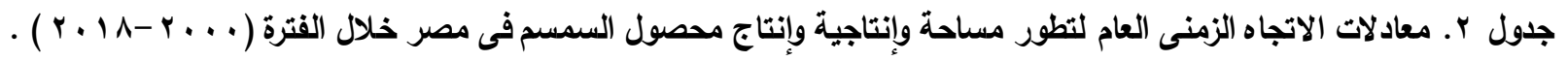

\begin{tabular}{|c|c|c|c|c|c|}
\hline معدل الزيادة أو & المتوسط & $\mathbf{F}$ & $\mathbf{R}^{2}$ & المعادلات & المتغيرات \\
\hline \multirow{2}{*}{-} & \multirow{2}{*}{ Vr.Vr } & \multirow{2}{*}{0.29} & \multirow{2}{*}{0.30} & $\hat{Y}=71.15+0.26 x$ & المساحة المزروعة بالألف \\
\hline & & & & $(13.07)^{* *} \quad\left(0.54^{-}\right.$ & فدان \\
\hline$\cdot . v 1$ & 纟.or & 27.09 & 0.61 & $\begin{array}{c}\hat{Y}=4.21+0.03 x \\
(59.30)^{* *} \quad(5.21)^{* * *}\end{array}$ & الإنتاجية الفانية بالأردب \\
\hline- & MrV.E. & 0.37 & 0.23 & $\begin{array}{c}\hat{\mathrm{Y}}=339.43-1.20 \mathrm{x} \\
\left(15.19^{* *} \quad(-0.61)^{-}\right.\end{array}$ & الإنتاج الكلي بالألف أردب \\
\hline
\end{tabular}

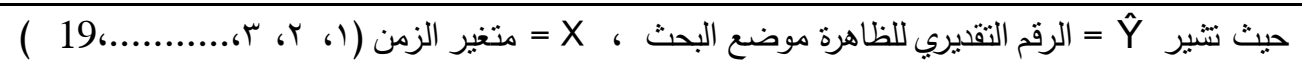

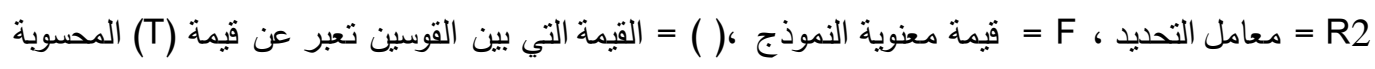

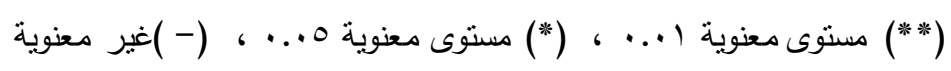
الانصدر : جمعت وحسبت من الجدول رقم (1). تتأثر بعدد من العوامل التي قد تعمل متقردة أو مجتمعة في تأثيرها

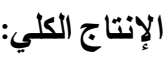

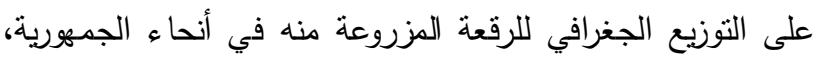

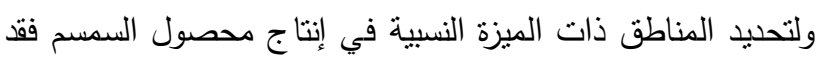

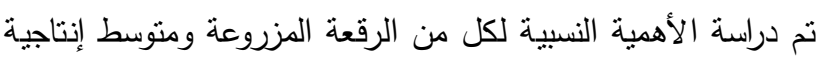

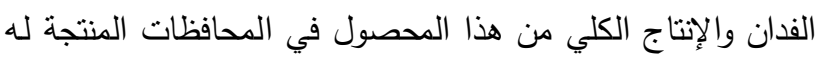

بالجمهورية. وتتشير البيانات الواردة بالجدول رقم (†) إلي أن منوسط المساحة

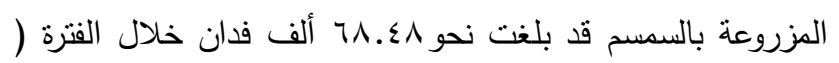

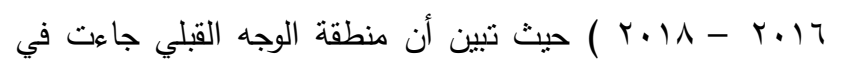

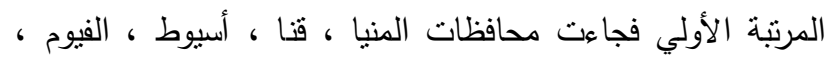

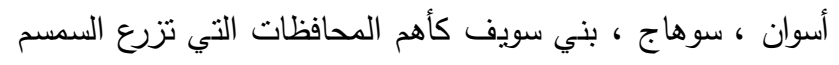

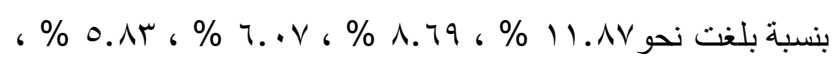

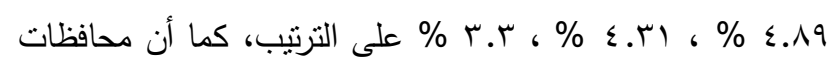

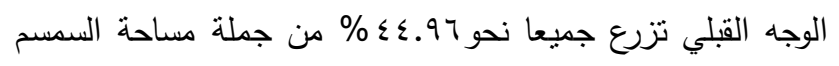

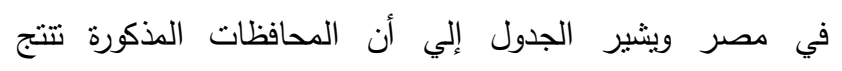

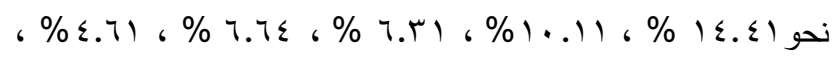
ـ.

باستقراء البيانات الواردة بالجدول رقم(1) تبين أن متوسط أناط

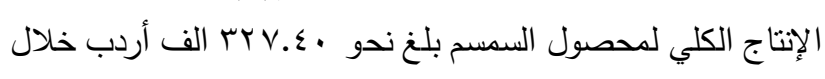

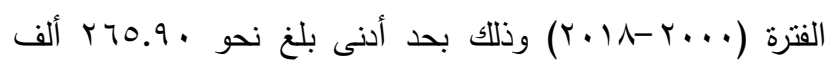

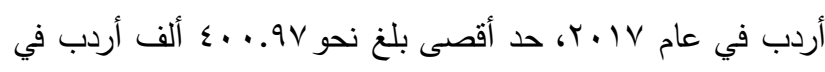

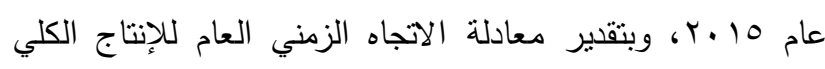

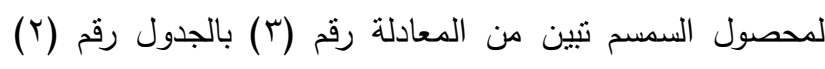
تتاقص الإنتاج الكلي لمحصول السمسم بمقدار غير معنوي احصائيا

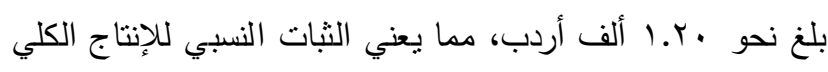

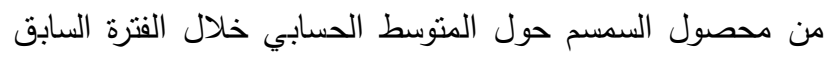

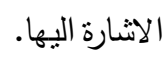

\section{التوزيع الجغرافى لإنتاج محصول السمسم فى مصر :}

تنتاين كل من الرقعة المزروعة وغلة الفدان والإنتاج من محصول السمسم في المحافظات المختلفة في مصر ويزرع السمسم في مصر بمساحات صغيرة نسييا وهو محصول صيفي تجود زراعته

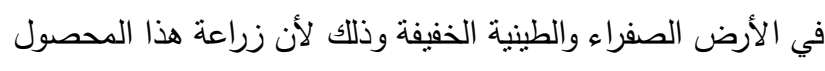


جلول r. الأهمية النسبية لمتوسط المساحة والإنتاجية والإنتاج الكلي من محصول السمسم في أهم المحافظات المنتجة له في مصر خلال

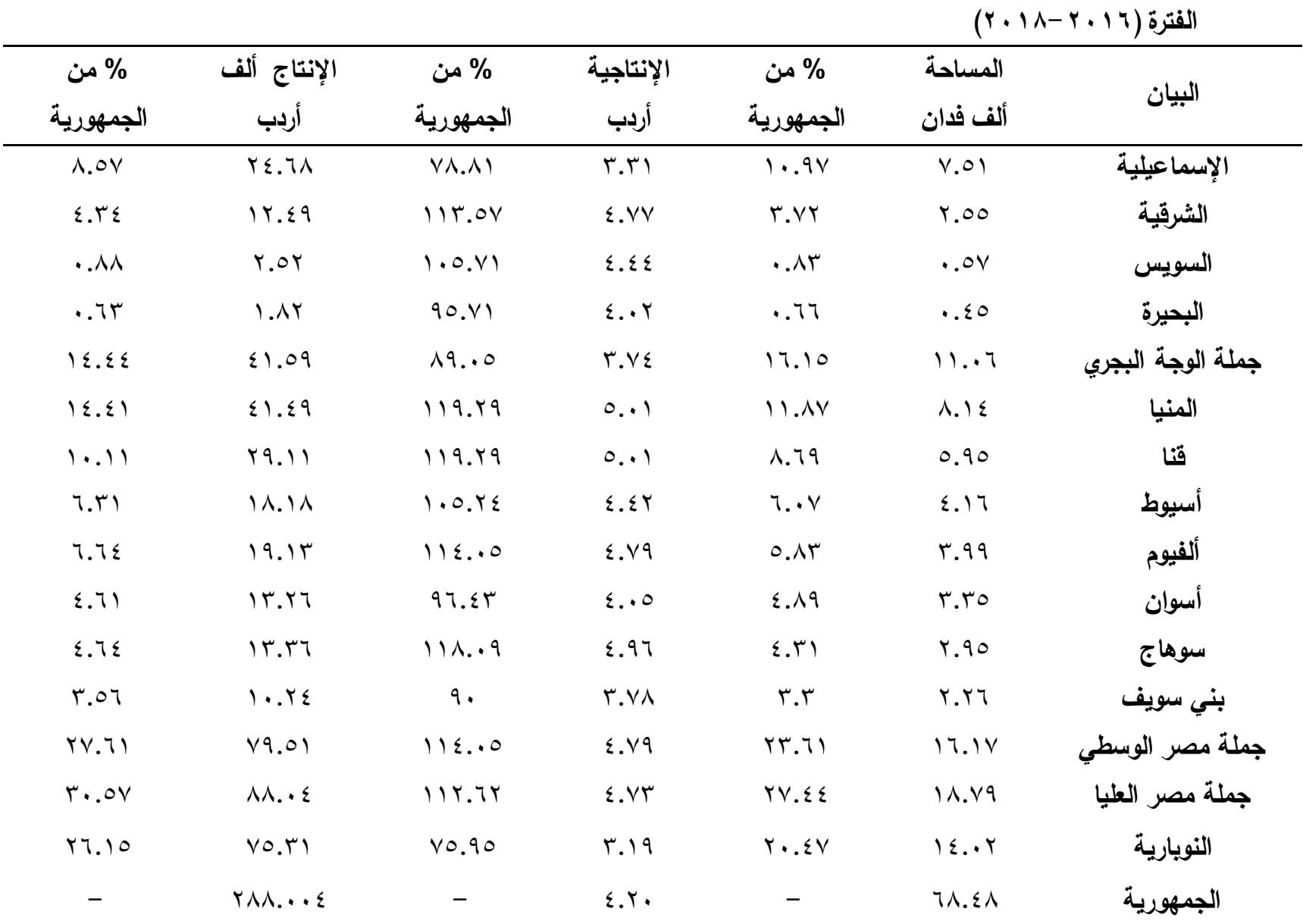

المصدر : جمعت وحسبت من بيانات :وزارة الزراعة واستصلاح الأراضي ، نشرة الاقصاد الزراعي ، أعداد مختلفة.

تطور التكاليف الإنتاجية :

توضح بيانات الجدول رقم (£) ان منوسط التكاليف الكلية بلغ

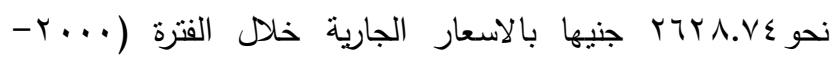

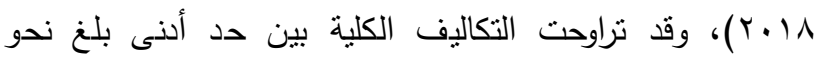

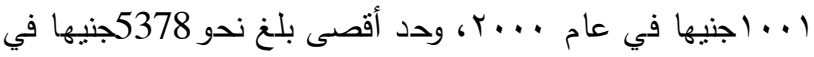

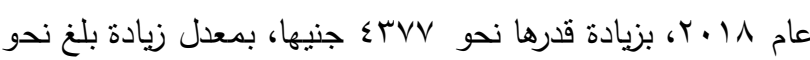

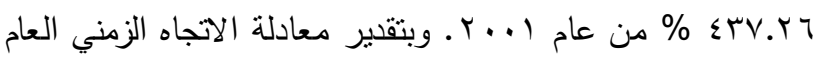

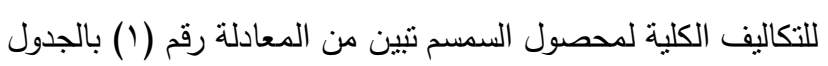
رقم (0) زيادة التكاليف الكلية للفدان من محصول السمسم بمقدار

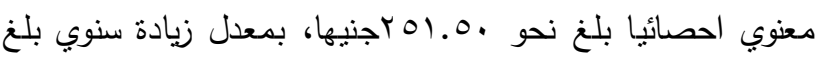

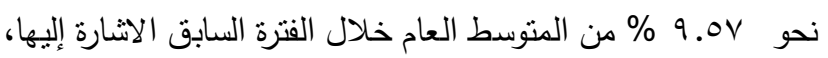

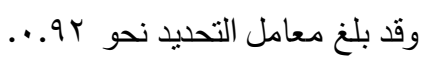

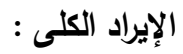

توضح بيانات الجدول رقم(ع ) أن متوسط الإيراد الكلى للفدلن

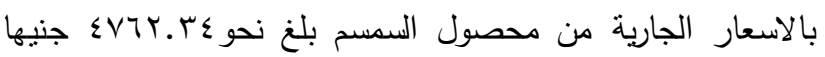

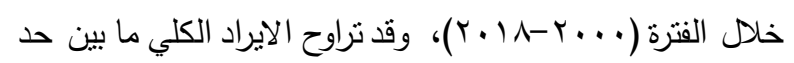

جملة إنتاج المصصول في مصر، وبإنتاجية فدانية بلغت نسبنها نحو r. الفدانية على مسنوي الجمهورية، و ونأني في المرنبة الثانية منطقة

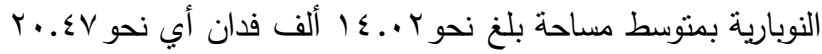

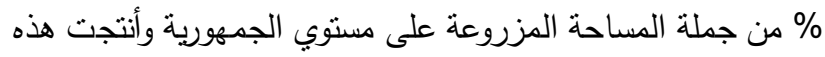

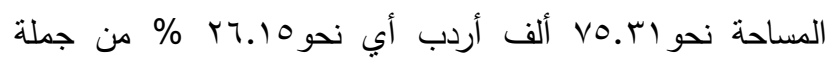

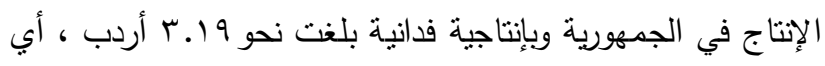
نحو V0.90 \% من جملة إنتاجية الجمهورية، وتأني في المرنبة الثالثة منطقة الوجه البحري حيث جاءت محافظات الإسماعيلية ،

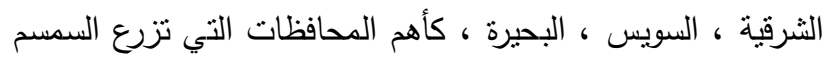

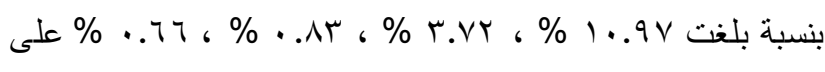
التزتيب من جملة الرقعة المزروعة على مستوي الجمهورية وأنتجت

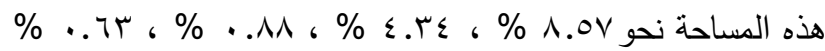
على الترتبب من إنتاج الجمهورية وبإنتاجية فدانية بلغت نسبتها

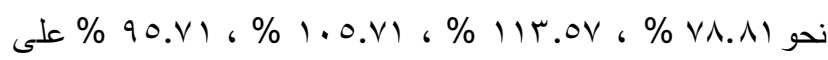
الترنيب من إنتاجية الجمهورية خلاد الفترة السابق الاثارة اليها. 
جدول ـ. تطور التكاليف الكلية والإيراد الكلى وصافى العائد الفدانى والسعر المزرعي ونسبة العائد للتكاليف وأريحية الجنية المنفق وأريحية القيمة: بالجنيه

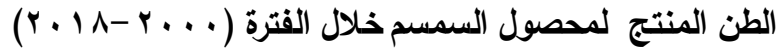

\begin{tabular}{|c|c|c|c|c|c|c|c|}
\hline اربحية الطن & اربحية الجنية & نسبة العائد & السعر & العائد الفدانى & الايراد & الإنتاليف & السنة \\
\hline IVA.1E &. .10 & 1.10 & rq9 & $V \leqslant \Lambda$ & $1 v \leqslant 9$ & $1 \ldots 1$ & $r \ldots$ \\
\hline rY $\{. .0$ & .990 & 1.9. & $\varepsilon \cdot V$ & 904 & 19.7 & $1 \ldots \varepsilon$ & $r . .1$ \\
\hline YII. &.$\wedge \varepsilon$ & $1 . \wedge \varepsilon$ & $\leqslant 11$ & 191 & 1971 & חד & $r \ldots r$ \\
\hline r.A.IV &.$\Delta r$ & $1 . \wedge r$ & $\varepsilon 1 \wedge$ & $\wedge \wedge 9$ & 1980 & 1.17 & r. r \\
\hline rTV.r. & 1.11 & $r . \wedge$ & $\leq 71$ & 1187 & מדצr & $1 . \lambda V$ & $r . . \varepsilon$ \\
\hline$Y \mid \wedge .91$ & .71 & 1.71 & $\{91$ & $1 \cdots v$ & $r \leqslant q$. & I & $r . .0$ \\
\hline סז.qץr &.$V r$ & $1 . V r$ & $01 \leq$ & 11.1 & צחדץ & 10ro & $r . . r$ \\
\hline rqג.. &. .99 & 1.99 & $v \cdot \Lambda$ & 9ז1 ו & rv.. & $|\wedge 7|$ & $r . . v$ \\
\hline عا..וד & .71 & 1.71 & 1.9 & 1705 & $\varepsilon .9 \pi$ & $r \leq r q$ & $r . \lambda$ \\
\hline rvi.A. & זד. & חד. & $9 \cdot 1$ & 1079 & $\varepsilon \cdot V V$ & ro. & $r . . q$ \\
\hline$\varepsilon \cdot V .99$ &. .79 & 1.79 & דים & IVAV & $\varepsilon r \wedge$. & roq & $r \cdot 1$. \\
\hline rar.lv &. .71 & 1.71 & $q V Y$ & $1 \wedge \cdot \varepsilon$ & $\Sigma \vee \neg \wedge$ & rq7 & $r .11$ \\
\hline או.זדV & $1 . \cdot v$ & $r . . V$ & irov & $r \leq 0 V$ & $779 \leq$ & מry & $r .1 r$ \\
\hline VAE.VY & 1.1. & r.l. & سqسו & roqs & T^V. & Vדr & r. \\
\hline VOV.ET & 1.11 & r..A & $1 \leq r q$ & $r v \cdot \varepsilon$ & VIYE & $r \leqslant r$. & $r \cdot 1 \leq$ \\
\hline$V \cdot \varepsilon . r$. & $.9 \leq$ & $1.9 \varepsilon$ & $1 \leq \vee \wedge$ & ror & (94) & rovg & $r .10$ \\
\hline$\varepsilon \cdot V . T \Lambda$ & צח. & צח. & $101 \%$ & $191 r$ & VTr & צrשo & $r .17$ \\
\hline $1 \ldots 70$ &.$V Y$ & $1 . V Y$ & 1914 & r.99 & $\wedge \wedge .0$ & 01.7 & $r . i v$ \\
\hline I.VA.VV & $1 . .1$ & $r . .1$ & r)A & $0 \leqslant T V$ & 1.ArE & orkv & r.11 \\
\hline$\leq \forall 1 . \leqslant 1$ &.$\wedge 1$ & 1.11 & $q \wedge \Sigma . \% \vee$ & rITO.VT & EVTY.TE & YTYA.VE & المتوسط \\
\hline
\end{tabular}

المصدر: وزارة الزراعة واستصلاح الاراضى، قطاع الثئون الاقتصادية، الإدارة المركزية للاقتصاد الزراعى، نشرة الاقتصاد الزراعى، أعداد مختلفة.

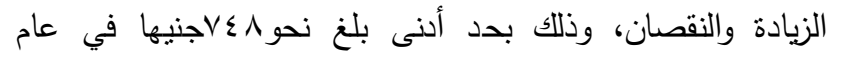

T....

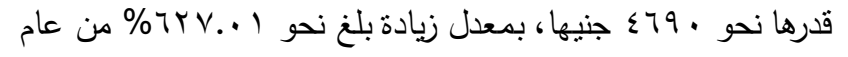

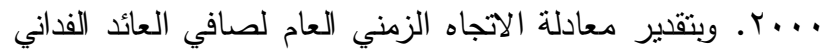

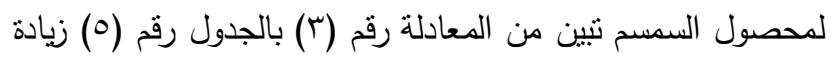
صافي العائد الفداني من محصول السمسم بمقدار معنوي احصائيا

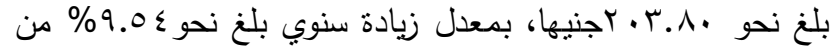
المتوسط العام خلا الفترة السابق الاثارة اليها، وقد بلغ معامل لعل

$$
\begin{aligned}
& \text { التحليد نحو 0Vo... } \\
& \text { السعر المز رعى : }
\end{aligned}
$$

يوضح الجدول رقم(§) أن منوسط السعر المزرعي للطن من

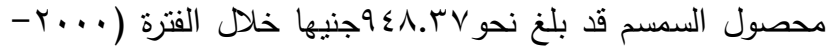

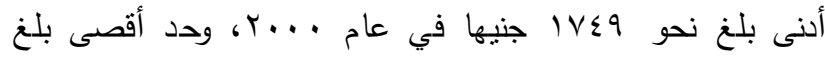

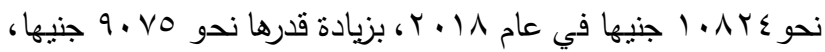

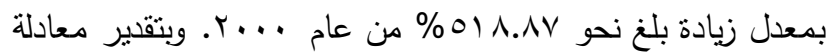
الاتجاه الزمني العام للإيراد الكلي لفان السمسم تيين من المعادلة رقم

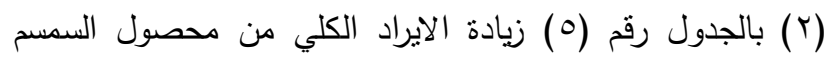

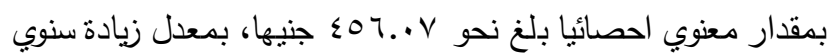
بلغ ندو 9.01 \% من المتوسط العام خلال الفترة السابق الاشارة إليها

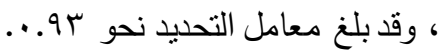
صافى العائد الفدانى : توضح بيانات الجدول رقم(ع) أن متوسط صافي العائد الفداني

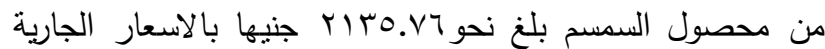

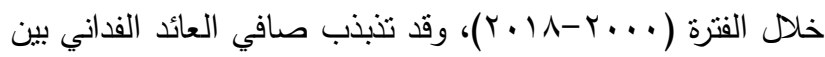


نسبة إجمالي الإيراد الكلى إلى التكاليف الكلية:

وهذا المقياس عبارة عن النسبة بين قيمة الإنتاج إلى تكلفة

عناصر الإنتاج المستخدمة فى العملية الإنتاجية ، أى أن هذا المعيار يتتاول شطري العملية الإنتاجية في صورتها النقدية وهذا المقياس يتيح المقارنة بين الوحدات الإنتاجية المختلفة وكذللك بين الأنماط المزرعية، ولقد بلغت هذه النسبة نحو اله. اجنيها خلال

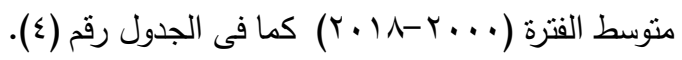
أريحية الطن المنتج من محصول السمسم :

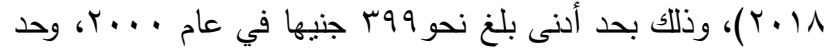

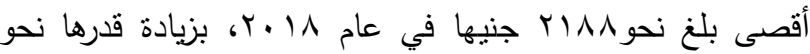

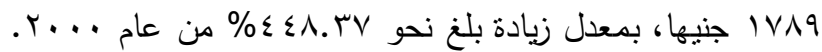
وبتقدير معادلة الاتجاه الزمني العام للسعر المزرعي لمحصول السمسم تنين من المعادلة رقم (ع) الواردة بالجدول رقم (0) زيادة السعر المزرعي لمحصول السمسم بمقدار معنوي احصائيا بلغ نحو |

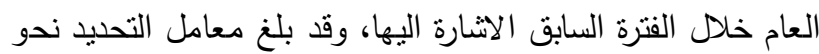
..91

وهذا المقياس عبارة عن قسمة صافي العائد الفداني علي

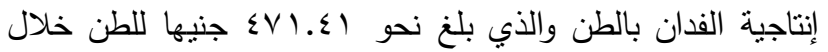

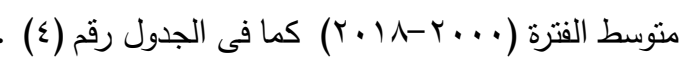

جاول ه. معادلات الاتجاة الزمني العام للتكاليف الكلية والايراد الكلي وصافي العائد الفداني والسعر المزرعي لمحصول السمس فى مصر

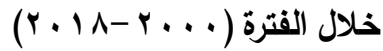

\begin{tabular}{|c|c|c|c|c|c|c|}
\hline معلل الزيادة او & المتوسط & $\mathbf{F}$ & $\mathbf{R}^{2}$ & المعادلات & البيان & 5 \\
\hline $9.0 \mathrm{~V}$ & YTrA.VE & 202.10 & 0.92 & $\begin{array}{l}\hat{Y}=113.72+251.50 x \\
(0.56)^{-}(14.22)^{* *}\end{array}$ & التكاليف الكلية & 1 \\
\hline 9.01 & SVTY.TE & 199.83 & 0.93 & $\begin{array}{c}\hat{Y}=201.61+456.07 x \\
(0.54)-(14.14)^{* * *}\end{array}$ & الايراد الكلي & r \\
\hline $9.0 \leqslant$ & YITO.VT & 49.82 & 0.75 & $\begin{array}{l}\hat{Y}=97.71+203.80 x \\
(0.30)^{-}(7.06)^{* * *}\end{array}$ & الفاداني (جنيه) & $r$ \\
\hline 9.7. & $9 \wedge \varepsilon . \mu \vee$ & 201.60 & 0.91 & $\begin{array}{c}\hat{Y}=39.78+94.46 x \\
(0.52)^{-}(14.20)^{* *}\end{array}$ & السعر المزرعي & $\varepsilon$ \\
\hline
\end{tabular}

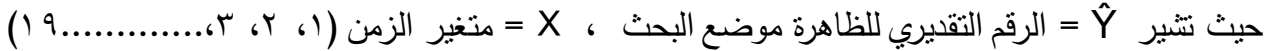

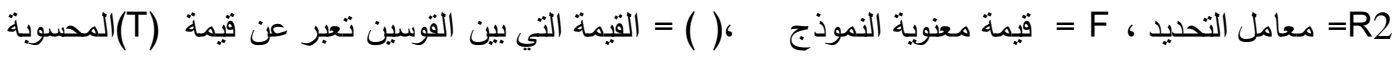

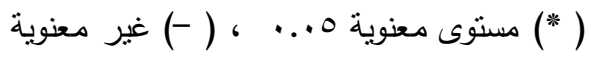
(... ) مستوى معنوية (*) المصدر : حسبت من الجداول رقم ( ؟).

تقدير دالة استجابة عرض محصول السمسم على مستوى الجمهورية:

تم تقلير دالة استجابة عرض محصول السمسم في مصر

ويتم الحصول على هذا المعيار بقسمة صافي العائد الفدانى على إجمالي التكاليف للفدان شاملة الإيجار والأجور وغيرها، وتعكس للتعرف على العوامل المختلفة التي بمكنها التأثثير على المساحة المزروعة بالمحصول، وهنا لا تؤخذ مساحة السمسم في نفس العام لعدم إمكانية التوسع في زراعة المحصول بعد زراعته ولكن تكون في العام التالي وقد استخدم نموذج مارك نيرلوف mark nerlove حيث زيادة هذا المعيار ارتفاع أربحية الجنيه المنفق، ارتفاع معامل الكفاءة الاقتصادية، وتبين من الجدول رقم(§) أن متوسط أربحية الجنيه المنفق فى الموسم لمحصول السمسم بلغ نحو ایه. · جنيها خلال

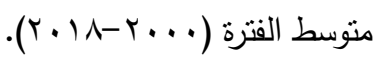
أنه من أفضل النماذج لقياس هذه الدالة. ويفترض هذا النموذج أن أهم العوامل المؤثرة على مساحة محصول السمسم في مصر خلال

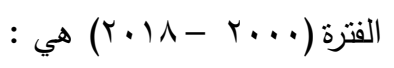

أربحية الجنيه المنفق : 


\section{Alshaima Mohamed Fangary., 2021}

أهم العوامل الاقتصادية المؤثزة على الرقعة المزروعة بمحصول

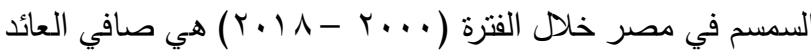
الفداني لكل من محاصيل الفول السودانى، الكوسة الصيفى، الخيار الصيفى، السمسم على الترتيب: لوص

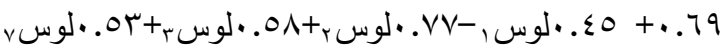

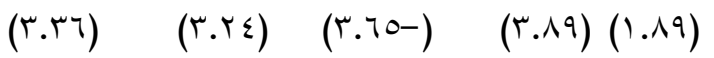
$r \cdot r u=$ ف $\quad \cdot .9 \cdot=r$

حيث ص^ = = القيمة التقليرية للرقعة المزروعة من السمسم في السنة الحالية بالألف فدان سا = = صافي العائد الفداني لمحصول الفول السوداني بالجنيه في

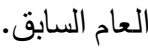
سr = صافي العائد الفداني لمحصول الكوسة الصيفي بالجنيه في

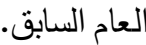
سr = صافي العائد الفداني لمحصول الخيار الصيفي بالجنيه في

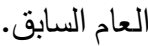
سv = صافي العائد الفداني لمحصول السمسم بالجنيه في العام

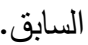
رץr = معامل التحيد، ف = = معنوية النموذج، والقيمة التي بين الاقواس = قيمة ت المحسوبة المصدر:جمعت وحسبت من بيانات: وزارة الزراعة واستصلاح الاراضى، قطاع الثئون الاقتصادية ، نشرة الاقتصاد الزراعى، أعداد

مختلفة.

التقدير الاحصائى لاوال إنتاج وتكاليف محصول السمسم فى محافظة قنا.

يتضدن هذا الجزء تقدير دوال الإنتاج والتكاليف على مستوى عينة الدراسة لمزارعي السمسم بمحافظة قنا بالفئات الحبازية الثلاثة

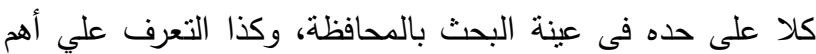
المشكلات الإنتاجية التى تواجه مزارعى المحصول بالمحافظة

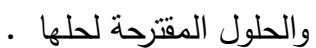

توصيف عينة الدراسة لمحصول السمسم بمحافظة قنا: تم اخنيار عينة طبقية عشوائية على مستوى المحافظة، ثم

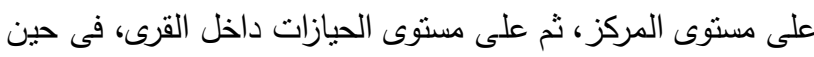
تم اختيار المزارعين عشوائياً من جداول الارقام العشوائية وقسمت متركي

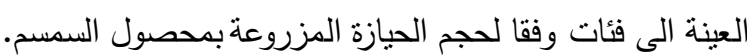

سا = صافي العائد الفداني لمحصول الفول السوداني بالجنيه في

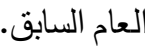

سr = صافي العائد الفداني لمحصول الكوسة الصيفي بالجنيه في

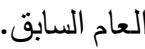
سr = صافي العائد الفداني لمحصول الخيار الصيفي بالجنيه في

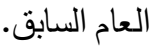

سء = صافي العائد الفداني لمحصول الباذنجان الصيفي بالجنيه في

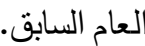
سه = صافي العائد الفداني لمحصول البطاطس الصيفي بالجنيه في

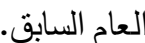
ست = صافي العائد الفداني لمحصول الطماطم الصيفي بالجنيه في

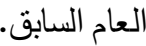
سv = صافي العائد الفداني لمحصول السمسم بالجنيه في العام السابق. وباستخدام صافي العائد للمحاصبل السابقة (وهي المحاصبل المنافسة للسمسم في اللورة). تشير النتائج المتحصل عليها من دالة استجابة العرض أن أهم المتغيرات المستقلة ذات التأثير على الرقعة المزروعة بمحصول السمسم هي صافي العائد الفداني لمحصول الفول السوداني في السنة السابقة (س))، وصافي العائد الفداني لمحصول الكوسة الصيفي في السنة السابقة(سr)، وصافى العائد الفدانى لمحصول الخيار الصيفى فى السنة السابقة(سب)، وصافي العائد الفداني لمحصول السمسم في العام السابق (سv)، ولقد ثبت المعنوية الإحصائية لمعاملات الانحدار المقدرة عند مستوى معنوية 1... ويشير معامل التحديد إلي أن نحو .9\% من التغيرات التى تحدث فى مساحة محصول السمسم فى مصر ، ترجع إلى التغيرات الحاثنة فى المتغيرات التى تضدنها النموذج. كما نبين وجود تأثير سلبي لصافي العائد الفداني لمحصول الكوسة الصيفي بالجنيه في السنة السابقة (سr) وكان ثاثيره معنوي، وبتقدير مرونة استجابة العرض لكل من صافي العائد الفداني لمحصول الفول السوداني، الكوسة الصيفى، الخيار الصيفي والسمسم فقد بلغت نحو 0ـ ... VV نحو 1\% من صافي العائد الفداني لمحصول الفول السوداني، الخيار الصيفي، والسمسم في العام السابق يؤدى إلى تغير قدره نحو

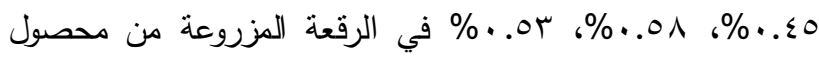
السمسم في مصر على الترتيب، في حين أن أي تغير قدره ا \% في صافي العائد الفداني لمحصول الكوسة الصيفي يؤدي الي تغير المساحة المزروعة من السمسم بنحو VV. . . . . كما قدرت مرونة استجابة عرض صافي العائد الفداني لمحصول الخيار الصيفي في السنة السابقة والتي بلغت نحو V9. ..، ومن العرض السابق نتين أن 
اجمالى المساحة المزروعة بالمحافظة على الترنيب، وقد جاءت فى المرتبة الرابعة والخامسة والساسة كل من مركزي شنا، نجع

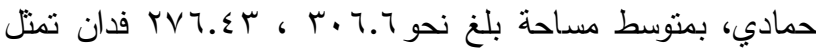
نحو 7 . . 1 \% \% ، 9.9 من اجمالى مساحة المحافظة على الترتيب ثم تلتها كل من مركز أرمنت، والوقف، وقفط، وأبونتت، وفرشوط بمتوسط مساحة بيلغ نحو

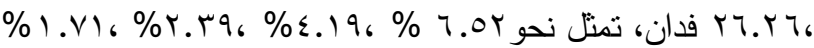

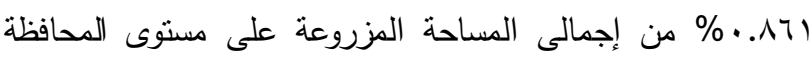
على الترتيب ومن العرض السابق يتيين أن مركز قنا جاء فى المرتبة الاولى من حيث المساحة المزروعة لذلكثم اخنياره كعينة البحث.

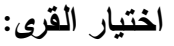

تم اختيار القرى بنفس طريقة اختبار المراكز بحيث تمثل اكبر مساحة بكل مركز إلا أنه روعى بدرجة كبيرة اختيار القرى التى بها فئات حيازية مختلفة، وذلك لتقسيم مجتمع الدراسة لفئات حيازية مختلفة حيث ثبين من الجدول رقم (V) أن قرية بندر قنا والقناوية والإشراف الثرقية والعسالية والأشراف القبلية والغربية والحميدات كانت أهم القرى من حيث المساحة المزروعة بالسمسم حيت مثلت

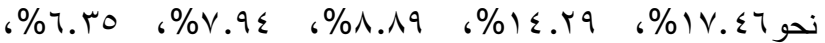
0.07\% 0.07 0. 0 من جملة مساحة مركز قنا علي الترتيب والتي تقدر بنحو • rף فدان ومثلت باقي القرى نحو \.بr\% من جملة المركز كما هو موضح بالجدول رقم (V))، لذلك تم اخنتار قرية بندر قنا والقناوية كأهم قري مركز قنا لإجراء الدراسة الميدانية.

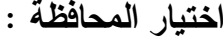

من دراسة التوزيع الجغرافى للمساحة المزروعة بمحصول

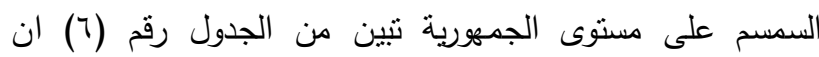

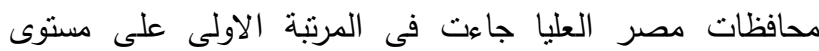

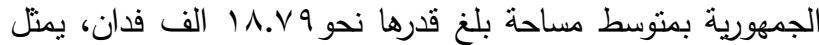
نحو ؟ ؟.rY\% من متوسط الرقعة المزروعة على مستوى الجمهورية، وجاءت محافظة قنا فى المرنبة الاولى على مستوى محافظات مصر

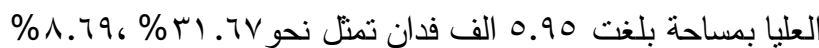
من متوسط الرقعة المزروعة على مستوى محافظات مصر العليا والجمهورية على الترتيب، وقد بلغ متوسط الإنتاجية الفدانية، والإنتاج

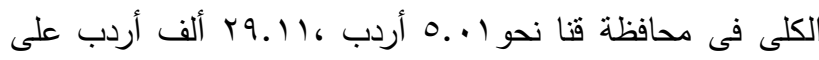

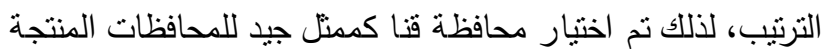

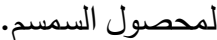
اختيار مراكز الاراسة لمحصول السمسم بمحافظة قنا :

(v) تضم محافظة قنا عشر مراكز إدارية موضحة بالجدول رقم هى ابوتشت، فرشوط، نجع حمادى، شنا، الوقف، قنا، قفط، قوص، نقادة، ارمنت،. وقد تم اختيار المركز الممنل للعينة طبقاً للأهمية النسبية للمساحة المزروعة بمحصول السمسم فى كل مركز وبتضح من الجدول أن مركز قنا يضم اكبر مساحة من محصول السمسم في

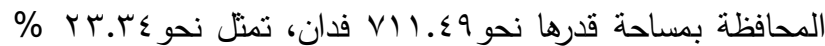
من المساحة المزروعة بالسمسم في المحافظة والبالغ قدرها

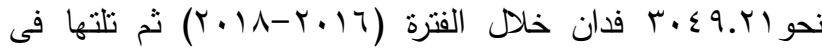
المرتبة الثانية والثالثة مركزي قوص ونقادة بمتوسط مساحة قدره نحو V.T.Y

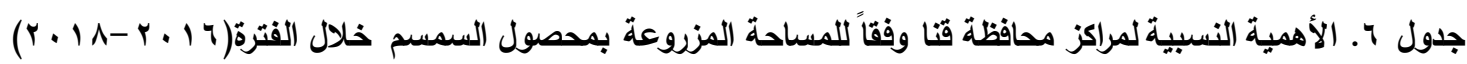

\begin{tabular}{|c|c|c|}
\hline الاهمية بالنسبة \% & متوسط المساحة & مركز \\
\hline$\% r$ & or... E & ابوتشت \\
\hline$\% 1$ & YT.YT & فرشوط \\
\hline$\% 1$. & ห人า. ะq & نجع حمادى \\
\hline$\% \backslash 1$ & $r .7 .7$ & 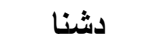 \\
\hline$\% 0$ & I rA & الوقف \\
\hline$\%$ Yr & $v 11 . \leqslant q$ & قنا \\
\hline$\%$ & VY.9A & قفط \\
\hline$\% \backslash \wedge$ & $0.7 . Y V$ & قوص \\
\hline$\% 17$ & $\varepsilon \varepsilon \varepsilon \ldots \varepsilon$ & نقادة \\
\hline$\% \vee$ & 191.9 & ارمنت \\
\hline$\% 1 \ldots$ & TVYY.VA & المحافظة \\
\hline
\end{tabular}

المصدر : وزارة الزراعة، واستصلاح الاراضى -قطاع الشئون الاقتصادية نشرة الاقتصاد الزراعى، اعداد متفرقة 
Alshaima Mohamed Fangary., 2021

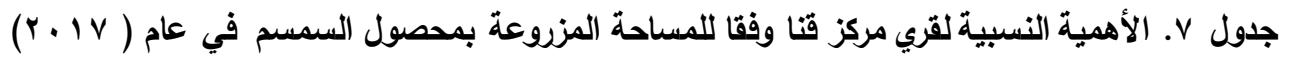

\begin{tabular}{|c|c|c|c|c|c|}
\hline$\%$ & المساحة & القرية & $\%$ & المساحة & القرية \\
\hline .90 & 1 & الطوابية & $1 V . \leqslant 7$ & 11. & بندر قنا \\
\hline$\therefore \vee 9$ & 。 & دندرة & 0.07 & ro & الحميدات \\
\hline 1.9 & ir & الترامسة & $1 \leq . \times 9$ & 9. & القناوية \\
\hline T.MA & & أبنود & r.) & $r$. & المخادمة \\
\hline r & r & تلاحين أبنود & 1.09 & 1. & الثيخ عيسي \\
\hline $1 . \leqslant r$ & 9 & كرم عمران & $r .97$ & ro & الإشراف البحرية \\
\hline .90 & 7 & المحروسة & T.ro & $\varepsilon$. & الإشراف القبيلة \\
\hline.$\vee \vee q$ & 0 & الدير الشرقي & 0.07 & ro & الإشراف الغربية \\
\hline$\therefore \vee 9$ & 。 & الاير الغربي & $\Lambda . \wedge 9$ & 07 & الأشراف الثرقية \\
\hline 1.09 & 1. & الطويرات & r.r & 10 & أولاد عمر \\
\hline T.0૬ & 17 & الجليوا & $1 . \varepsilon r$ & 9 & القوصة \\
\hline r.79 & ro & الصالحية & 1.9 & ir & الجحيرات \\
\hline V. $9 \varepsilon$ & 0 . & العسالية & 1.11 & v & جزيرة|الطوابية \\
\hline $1 \ldots$ & זי. & & & & جملة المركز \\
\hline
\end{tabular}

المصدر : مديرية الزراعة قنا سجلات قسم الإحصاء

المؤثرة على الإنتاج وهى عبارة عن العوامل المستقلة (المفسرة)

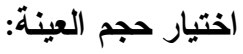
وتنين من الصورة اللوغاريتمية وجود علاقة موجبة بين إنتاج الفدان

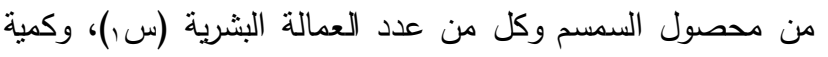

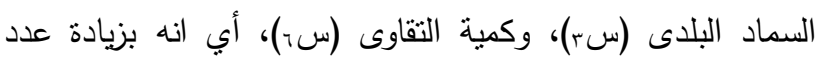

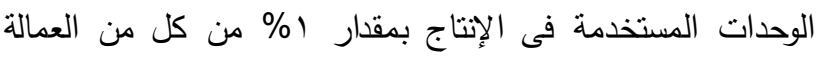

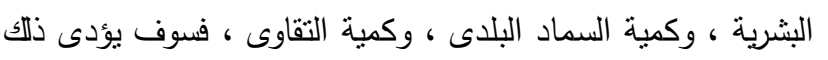

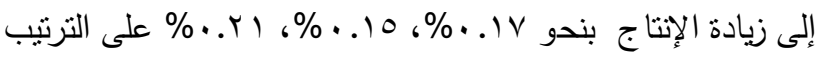
وذللك كما يتضح من الجدول رقم (^)، وقد ثبتت المعنوية الإحصائية لجميع المعلمات المقدرة كما تبين من المعادلة اللوغاريتمية وجود

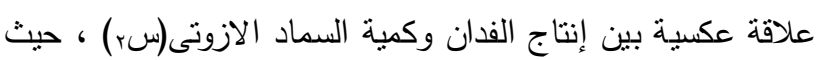

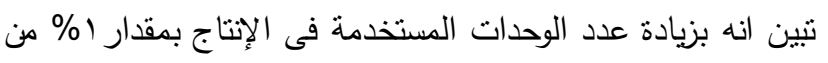

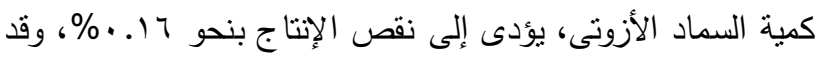

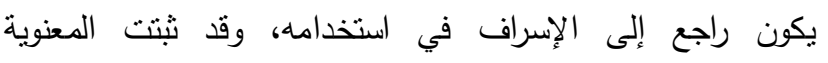

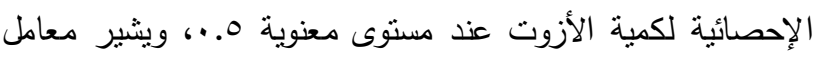

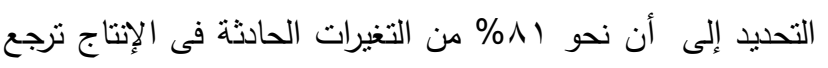

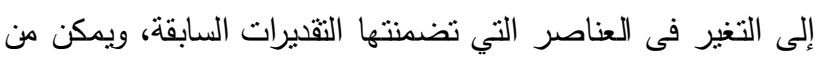

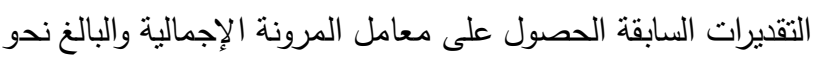

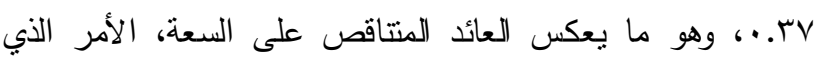

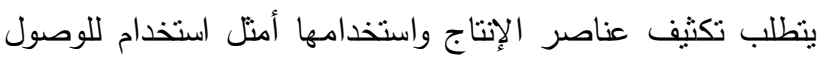
إلى المرحلة الاقتصادية للمنتج.

بلغ حجم عينة الدراسة ... مزارع (مفردة) بقري مركز قنا

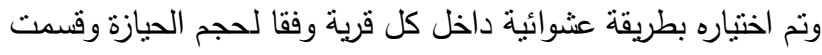

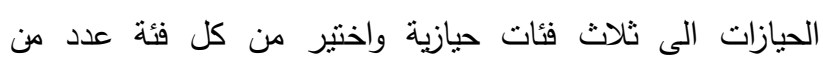
المزارعين تبلغ نسبتهم الى حجم العينة نفس النسبة بين عددهم

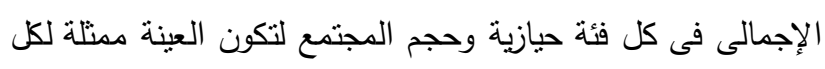

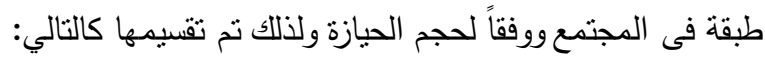
الفئة الحيازية الاولى: وتضم الحيازات التى تقل مساحتها عن فدان

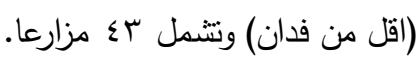
الفئة الحيازية الثانية: وتضم الحيازات التى تنراوح مساحتها من فدان منارعان

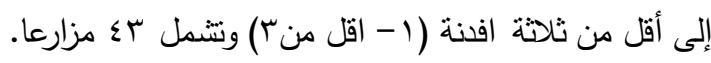

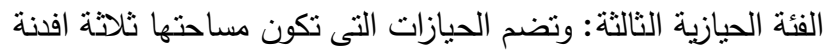
فأكثر وتثمل ع ا مزارعا.

- التقدير الاحصائى لدوال الإنتاج محصول السمس في محافظة

تقدير دالة الإنتاج للفئة الحيازية الأولى ( اقل من فدان ) تم تقلير دوال إنتاج محصول السمسم بالصور الإحصائية

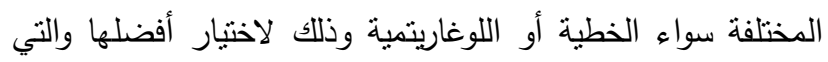

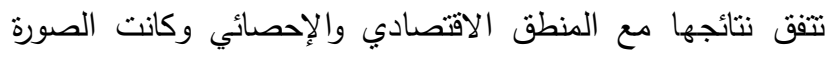

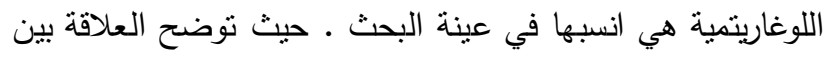
حجم إنتاج السمسم بالأردب وهو عبارة عن العامل التابع والعوامل 
المعلمات المقرة، و تبين أيضا وجود علاقة عكسية بين الإنتاج وكل من كمية السماد الازوتى (س2)، حيث أنه بزيادة عدد الوحدات

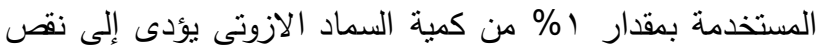
الإنتاج بنحو 9. .. م \%، وقد تأكدت المعنوية الإحصائية للسماد الأزوتى، ويشير معامل التحسيد إلى أن نحو بvV من التغيرات الحادثة فى الإتناج تعود إلى العناصر الإتناجية النى تضمنتها

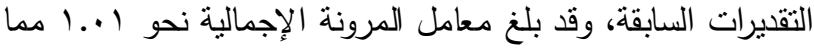

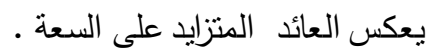

تقدير دالة الإنتاج للفئة الحيازية الثانية (من ا - أقل من ب أفدنة) تيين من الجدول رقم (^) و من الصورة اللوغاريتمية والتي هي انسب الصور المقدرة من ناحية المنطق الاقتصادي والإحصائي. وجود علاقة موجبة بين إنتاج الفدان وكل من عدد العمالة (س1) ، والري (س5)،وكمية التقاوي (س6) ، حيث انه بزيادة عدد الوحدات المستخدمة فى الإتتاج بمقدار 1\% من كل من عدد العمالة، والري،

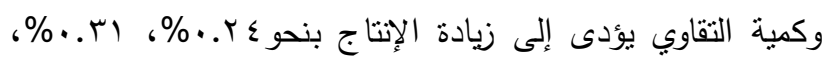

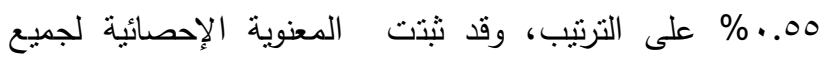

جدول ^. تقدير دوال إنتاج محصول السمسم في محافظة قنا

\begin{tabular}{|c|c|c|c|}
\hline ف & ru & المعادلات & الفئة الحيازية \\
\hline $1 T .04$ & $\cdot . \wedge 1$ & 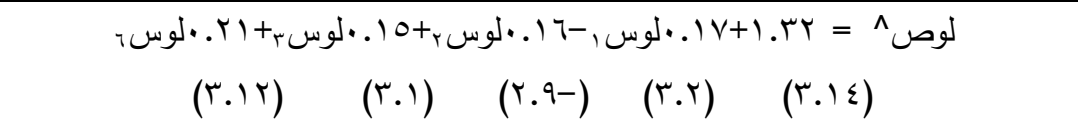 & $\begin{array}{c}\text { - الفئة الحيازية الأولي } \\
\text { (أقل من فدان) }\end{array}$ \\
\hline $1 . .07$ & $\because V V$ & 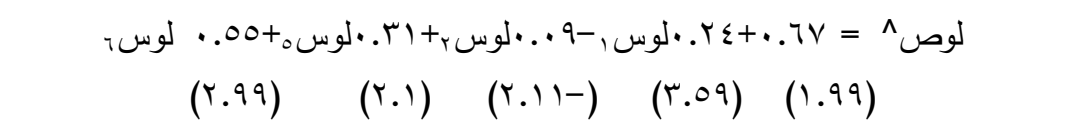 & 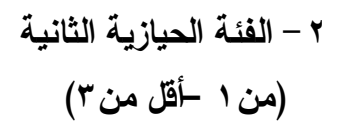 \\
\hline 10.91 & $\cdot \wedge$ & 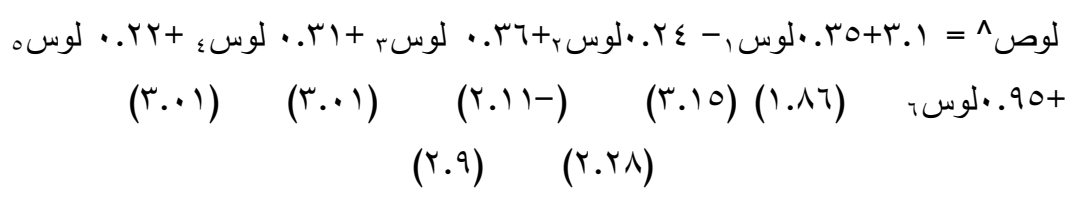 & 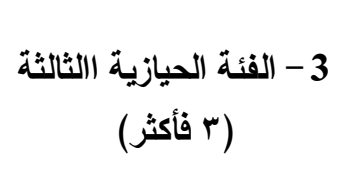 \\
\hline 07.47 & . . & 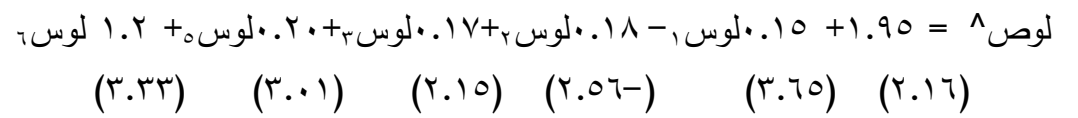 & ـ - إجمالى العينة \\
\hline \multicolumn{4}{|c|}{ 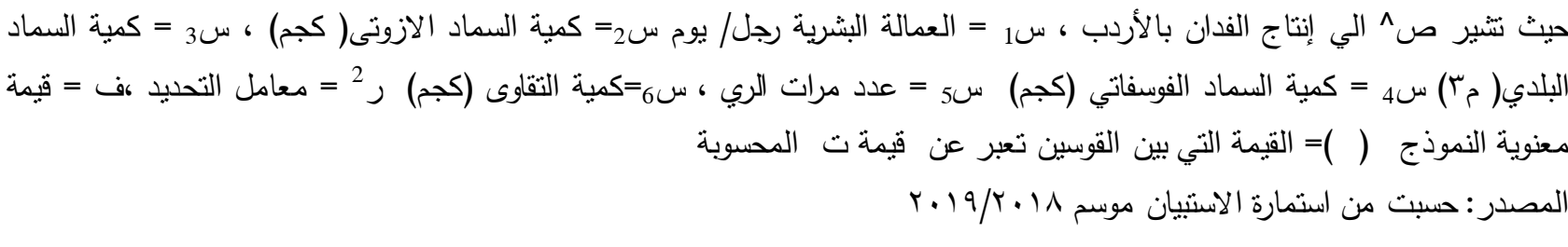 } \\
\hline
\end{tabular}

الإنتاج تعود إلى عناصر الإنتاج التى تضدنها التقير السابق، وقد بلغ معامل المرونة الإجمالية نحو 1.90 وهو ما يعكس العائد

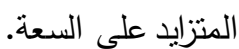

تقدير دالة الإنتاج لإجمالى عينة الدراسة لمحصول السمسم : باستقراء الييانات الواردة بالجدول رقم(^) نتين من الصورة اللوغاريتمية وجود علاقة موجبة بين الإتناج وكل من العمالة (س1)،

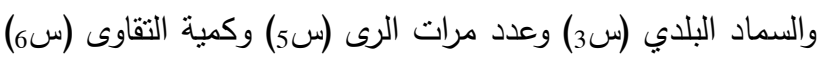

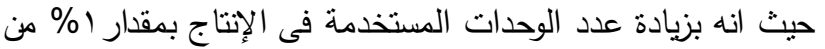
كل من العمالة، والسماد البلدي، وعدد مرات الرى، وكمية التقاوي

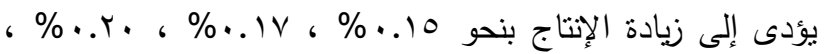

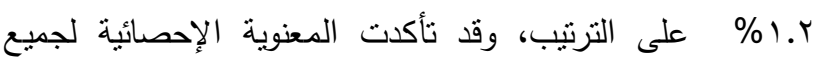
المعلمات المقدرة، كما نيين أيضا وجود علاقة عكسية بين الإنتاج وكمية السماد الازوتى (س) أي أنه بزيادة عدد الوحدات المستخدمة بمقدار 1\% من كمية السماد الازوتى يؤدى إلى نتاقص الإنتاج

\section{تقدير دالة الإنتاج للفئة الحيازية اثثالثة ( ب أفدنة فأكثر )} تثثير البيانات الواردة بالجدول رقم (^) أن الصورة اللوغاريتمية هي أفضل الصور المقدرة، والتي نيين وجود علاقة موجبة بين إنتاج الفدان من محصول السمسم وكل من العمالة البشرية (س1)، والسماد البلدي (س3)، والسماد الفوسفاتي (س4)، والري (س5)، وكمية التقاوي (س6) ،أي انه بزيادة عدد الوحدات المستخدمة فى الإتناج بمقدار

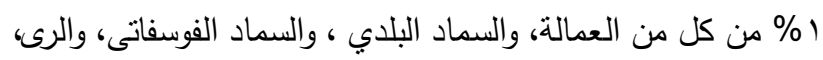

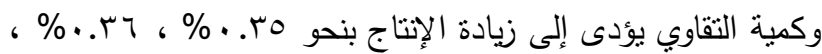

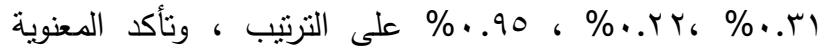
الإحصائية لجميع المعلمات المقدرة ماعدا السماد الفوسفاتى لم تنثت المعنوية الإحصائية له ، وتنين أيضا وجود علاقة عكسية بين إنتاج

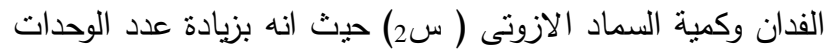
المستخدمة بمقدار / \% من السماد الازوتى يؤدى إلى نقص الإنتاج

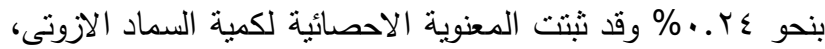

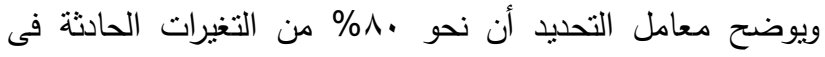


وحجم الإنتا ج لمحصول السمسم حيث ثبتت المعنوية الإحصائية عند

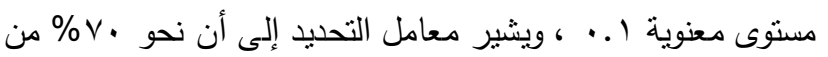
التغيرات الحادثة فى التكاليف الإنتاجية تعزى إلى التغير فى الكمية المنتجة من السمسم فى عينة المزارعين بنلك الفئة، ومن خلال هذه المعادلة تم حساب الحجم المحقق لأقل تكلفة إنتاجية ( الحجم الأمثل للإنتاج)، والحجم المعظم للإرباح. وقد بلغ الحجم المدني للتكاليف

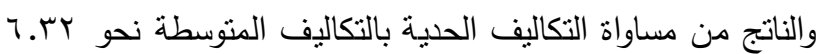
أردب، ويمكن الحصول على التكاليف المتوسطة من قسمة التكاليف باليف لإلهن الكلية على حجم الإنتاج، والتكاليف الحدية بإيجاد المشتقة الأولى للتكاليف الكلية، ويمكن تقدير الحجم المعظم للأرباح من مساواة التكاليف الحدية بالإيراد الحدى ( السعر) والذي بلغ نحو سم.7 أردب، كما يمكن تقلير معامل المرونة من خلال قسمة التكاليف

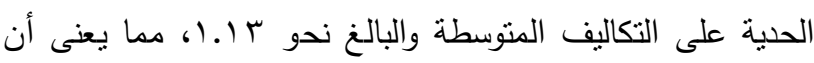
الإنتاج يتم فى المرحلة الاقتصادية.

تقدير دالة التكاليف للفئة الحيازية الثانية ( من 1 - اقل من r (أفذنة)

تنين من الجدول رقم (9) أن أفضل التقليرات الإحصائية لدول

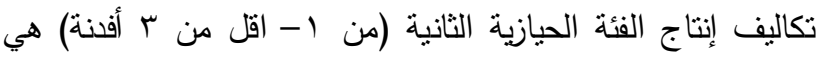

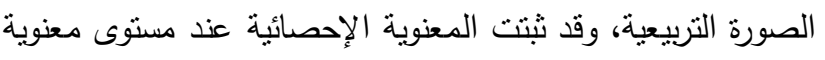

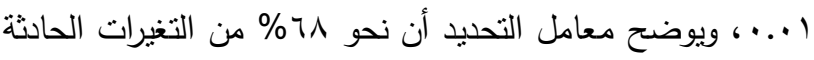

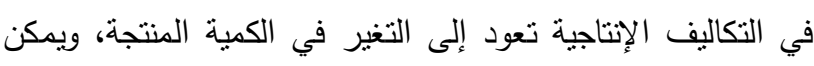

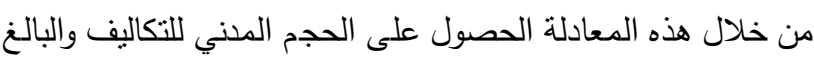

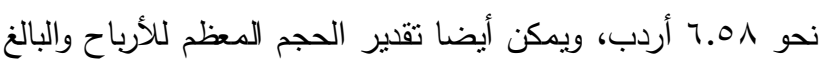

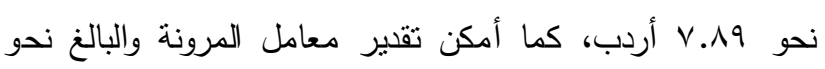
$\ldots 11$
بنحو 11.. \% وقد ثبتت المعنوية الإحصائية المقدرة له، ويشير

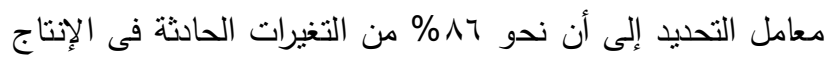

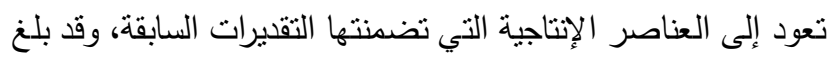

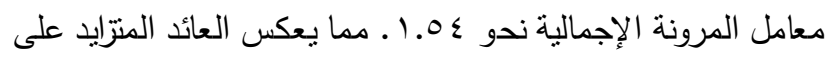

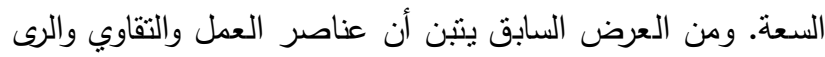

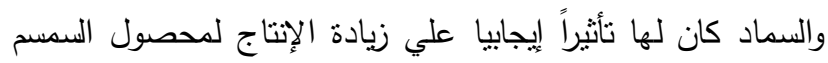

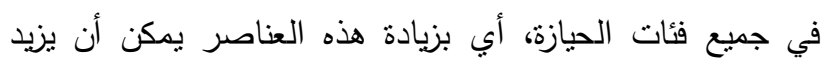

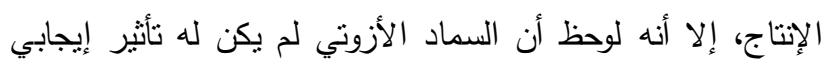

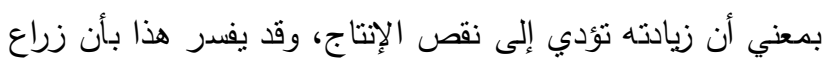

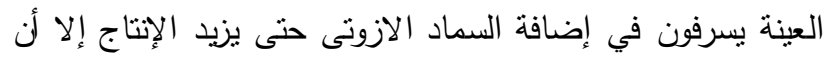
هذا الإسراف قد يؤدي إلى نتيجة عكسية.

التقدير الاحصائى لدوال التكاليف الإنتاجية لمحصول السمسم فى عينة الدراسة بمحافظة قنا تم تقير دوال التكاليف الإنتاجية واشتقاق كل من الحجم الأمتل

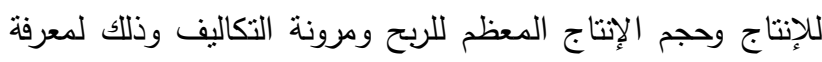

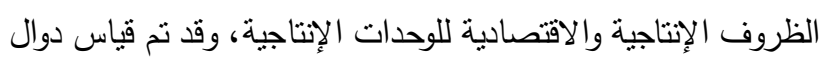
التكاليف الإنتاجية بعينة الدراسة في الصور الرياضية الخطية

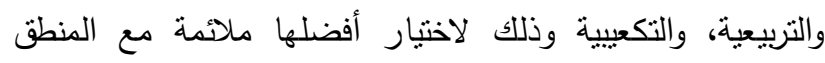
الاقتصادي والإحصائي في كل فئة.

تقدير دالة التكاليف الانتاجية بالفئة الحيازية الأولى

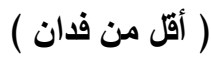

باستعراض التقيرات الإحصائية لدوال تكاليف الإنتاج

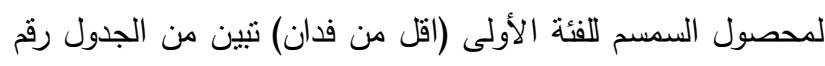

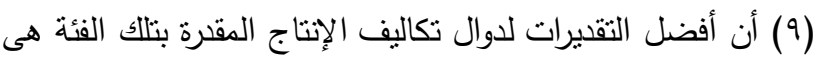
الصورة التربيعية والتى تيين العلاقة بين إجمالى التكاليف الإنتاجية

جدول 9 ـ تقدير دوال التكاليف الإنتاجية لمحصول السمسم في محافظة قنا بالعينة

\begin{tabular}{|c|c|c|c|}
\hline ف & 广ر & المعادلات & الفئة الحيازية \\
\hline 9.70 & $\therefore \vee \cdot$ & 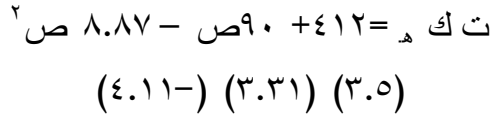 & 1 - الفئة الحيازية الأولي (أقل من فدان) \\
\hline r..ro &. .71 & 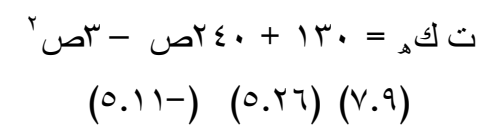 & ץ - الفئة الحيازية الثانية (من ا -أقل من ؟) \\
\hline 19.10 &.$v_{0}$ & 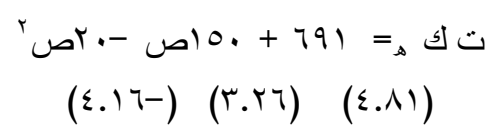 & 3- الفئة الحيازية الثالثة (ب فأكثر) \\
\hline$r \cdot \Lambda . r_{1}$ &.$V 7$ & 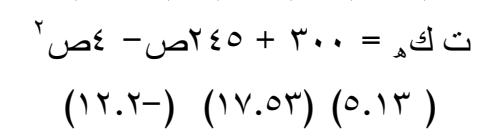 & ع - إجمالى العينة \\
\hline
\end{tabular}
حيث: ت ك= التكاليف الكلية ، صهـ = الإنتاجية الفدانية رب = معامل التحديد ،ف = قيمة معنوية النموذج

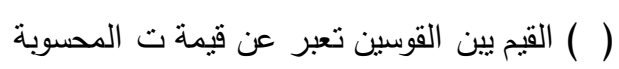

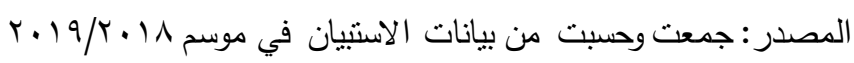


العينة، وقد يرجع ذلك إلى انخفاض المرونة المترتب عليها إنخفاض كفاءة استخدام عناصر الإنتاج في العدد المحدود من زراع هذه الفئة. المشكلات الإنتاجية التي تواجه مزارعي محصول السمسم فى

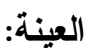

يواجة زراع محصول السمسم العديد من المشاكل المؤثرة سلبياً عل إنتاجية المحصول و كذا العائد المتوقع منه، ومن نتائج الاسنيان أمكن حصر عدد من هذه المشاكل كما في الجدول رقم (• (1الذي يبين أن مشكلة ارتفاع اسعار مستلزمات الإنتاج احتلت المرتبة الأولى نسبة بلغت نحو 17 \% من اجمالى مزارعى العينة، وتلتها فى المرتبة الثانية ارتفاع تكاليف العمالة وقلة الأيدي العاملة المدربة بنسبة بلغت نحو 10 \%، وتلتها فى المرنبة الثالثة، والرابعة كل من ضعف إنتاجية الصنف المزروع، ونقص الأسمدة وصعوبة الحصول عليها بنسبة بلغت نحو ع (\% ، ب ( \% على الترتيب وتلتها فى المرنبة الخامسة والسادسة كل من مشكلة انتشار الحشائش،

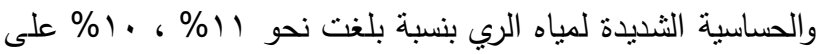
الترتيب، وتلتها كل من ارتفاع نسبة الاملاح فى التربة، والاصابة بالأمراض مثل ( الثلل ، والنبول ، نقص الجذور ) والظروف الجوية غير الملائمة وفرط الثمار، وعدم توافر الخدمات الإنتاجية ، وتعلد

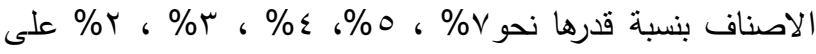

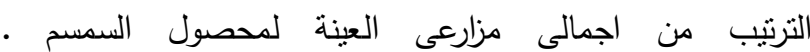

تقدير دالة التكاليف للفئة الثالثة ( من ب أفدنة فأكثر)

باستقراء التقديرات الواردة بالجدول رقم (9) تبين أن أفضل

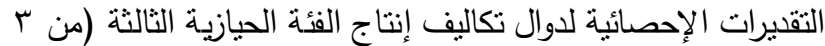

أفدنة فأكثر) هي الصورة التربيعية، حيث تأكدت المعنوية الإحصائية عند مستوى معنوية ا....، ويثير معامل التحديد إلى أن نحو ف \% من التغيرات الحانثة في التكاليف الإنتاجية تعود إلى التغير فى الكمية المنتجة من السمسم، وقد بلغ الحجم المدني للتكاليف نحو

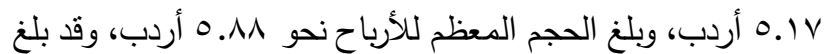

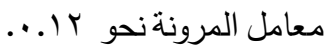

- تقدير دالة التكاليف لإجمالي العينة :

تبين التقيرات الواردة نفس الجدول رقم (9) أن أفضل التقيرات الإحصائية لدوال تكاليف إنتاج إجمالى العينة هى الصورة التربيعية، وقد ثبتت المعنوية الإحصائية عند مستوى معنوية ا (...، ويوضح معامل التحديد ان نحو \%V7 من التغيرات الحادثة فى التكاليف الإنتاجية تعزى إلى التغير فى الكمية المنتجة من محصول السمسم، وقد بلغ الحجم المنىى للتكاليف نحو سبـ أردب وقد بلغ الحجم

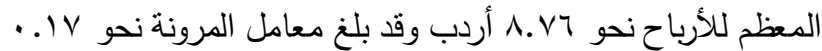
ومن العرض السابق بيضح أن الحجم المدني للتكاليف والمعظم للربح كان منخفضا في الفئة الحيازية الثالثة مقارنة بيقية الفئات وإجمالى جدول . . المشكلات أو المعوقات الإنتاجية لمحصول السمسم فى العينة مرتبة حسب أهميتها من وجهة نظر الزراع

\begin{tabular}{|c|c|c|c|}
\hline$\%$ & 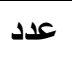 & 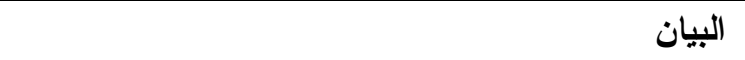 & الترتيب \\
\hline$\% 17$ & 90 & ارتفاع اسعار مستلزمات الإنتاج & 1 \\
\hline$\% 10$ & ᄉ० & ارتفاع تكاليف العمالة وقلة الايدى العاملة المدرية & r \\
\hline$\% 1 \leq$ & $\wedge$. & ضعف إنتاجية الصنف المزروع & $r$ \\
\hline$\%$ ir & $\vee \cdot$ & نقص الاسمدةوصعوبة الحصول عليها & $\varepsilon$ \\
\hline$\% 11$ & 70 & 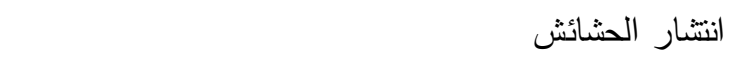 & $\bullet$ \\
\hline$\% 1$ & 7. & الحساسية الثديدة لمياه الرى & 7 \\
\hline$\% \vee$ & $\varepsilon$ & ارتفاعنسبة الاملاح بالتربة & v \\
\hline$\%$ & 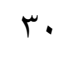 & الاصابة بالامراض مثل ( الثلل ، والذبول ، وتعفن الجذور ) & $\Lambda$ \\
\hline$\% \varepsilon$ & ro & الظروف الجوية غير الملأئمة وفرط الثمار & 9 \\
\hline$\%$ & r. & عدم توفر الخدمات الإنتاجية & $1 \cdot$ \\
\hline$\% r$ & $1 \cdot$ & 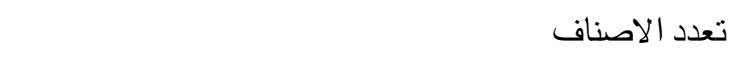 & 11 \\
\hline$\% 1 \ldots$ & & الإجمالي & \\
\hline
\end{tabular}

المصدر : جمعت من استمارة الاستيان 
والصرف والدراية والخبرة بزراعة محصول السمسم بنسبة بلغت نحو

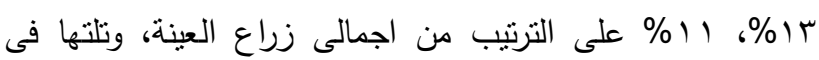
المرنبة الخامسة والسادسة حل مشكلة رى المحصول ليلا وزراعة

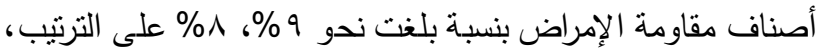
وتلتها كل من الحلول المقترحة لحل مشكلة الزراعة فى المعياد المناسب وتوفير الخدمات الإرشادية،وتوفير مبيدات مضمونة لمكافحة الحثائش، ومعاملة التقاوي بالمبيدات قبل الزراعة ( المطهرات) نسبة

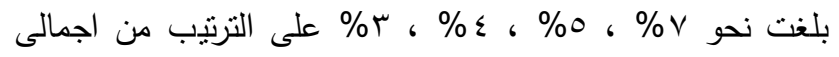

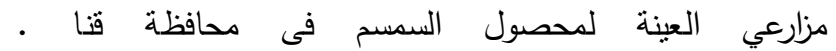

الحلول المقترحة لحل المشكلات المعوقات الإنتاجية لمحصول

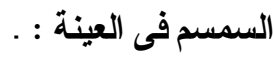

و في محاولة لوضع بعض المقترحات التي يمكن أن تحد من

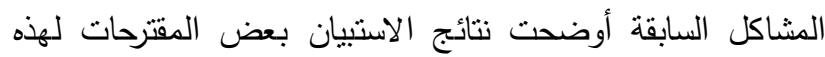
الحلول بالجدول رقم (1) (1) والذي يثير إلي أن الحلول المقترحة لحل بهل مشكلة توفير مستلزمات الإثتاج بأسعار مناسبة جاءت في المرنبة الأولى بندو اY \% نلتها فى المرنبة الثانية الدل المقترح لحل مشكلة

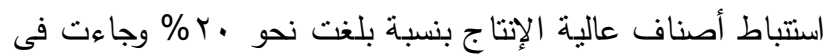
المرنبة الثالثة والرابعة لحلول المقترحة لدل مشكلة الاهتمام بالري

جدول 1 اـ أهم الحلول المقترحة لإزالة المعوقات والمشكلات الإنتاجية لمحصول السمسم فى العينة

\begin{tabular}{|c|c|c|c|c|}
\hline الترتيب & $\%$ & عدد & البيان & م \\
\hline 1 & $\% Y_{1}$ & $\wedge$. & توفير مستلزمات الإتناج باسعار مناسبة & 1 \\
\hline$\wedge$ & $\% 0$ & r. & توفير الخدمات الارشادية & r \\
\hline 0 & $\% 9$ & ro & رى المحصول ليلا & $r$ \\
\hline 9 & $\% \varepsilon$ & 10 & توفير مبيدات مضمونة لمكافحة الحشائش & $\varepsilon$ \\
\hline 1. & $\% r$ & 1. & معاملة التقاوى بالمبيدات قبل الزراعة ( المطهرات ) & 0 \\
\hline r & $\%$ r. & vo & استتباط اصناف عالية الإتتاج & 9 \\
\hline r & $\%$ & $\circ$. & الاهتمام بالرى والصرف & $v$ \\
\hline 7 & $\% \wedge$ & r. & زراعة اصناف نقاومة للمراض & $\wedge$ \\
\hline v & $\% \vee$ & ro & الزراعة فى الحصاد المناسب & 9 \\
\hline \multirow[t]{2}{*}{$\varepsilon$} & $\% 11$ & $\varepsilon$. & الدراية والخبرة بزراعة محصول السمسم & 1. \\
\hline & $\% 1 \ldots$ & rی. & \multicolumn{2}{|c|}{ الاجمالى } \\
\hline
\end{tabular}

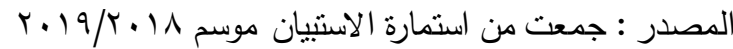

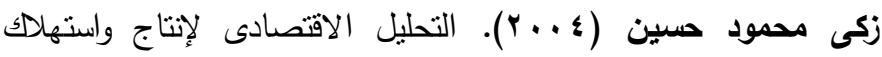

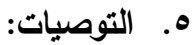

محصول السمسم فى مصر، نرة المحاصيل الزيتية فى مصر المؤشرات وبناءا علي النتائح يوصي البحث بمايلي : ا - - اسنتباط اصناف عالية الإنتاجية ، نتوائم مع الظروفوالمحدات، المؤتمر التاسع والثلاثون، معهد الدراسات والبحوث

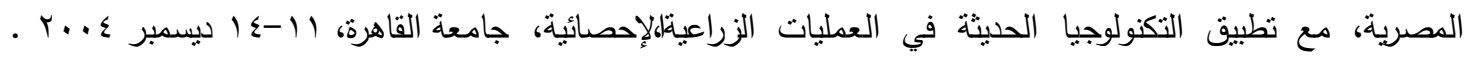
حسين حسن علي ادم، اقتصاديات إنتاج واستهلاك اهم محاصبل الزيوت بمساعدة الجهات البحثية والارشادية. r - العمل علي زيادة التسميد البلدي وخفض كميات السماد الكيماويفي مصر، رسالة دكتوراه، قسم الاقتصاد الزراعي، كلية الزراعة،جامعة عين شمس، حيث أن ذلك يؤدي الي زيادة الإنتاج وتخفيض التكاليف.

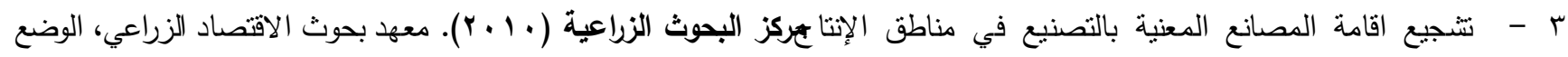
الرئيسية لنتجيع الزراع علي زيادة إنتاجهم والتوريد باسعار مناسبة. الراهن لإنتاج بعض المحاصيل الزينية في مصر(دراسة ميدانية) ،

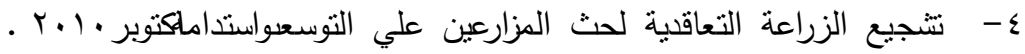
وزارة الزراعة واستصلاح الاراضى، قطاع الثنئون الاقتصادية،الإدارة المركزية للاقتصاد الزراعى، نشرة الاقتصاد الزراعى، اعداد مختلفة. زراعة محصول السمسم. ד.

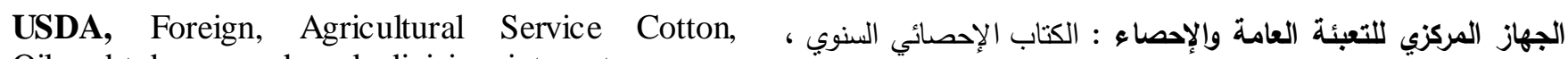
Oilseed tobacco and seeds division, internet. www.Food-industries.com.eg 


\title{
An economic study of sesame crop in Egypt
}

\author{
Alshaima Mohamed Fangary \\ Agricultural Economics Department, Faculty of Agriculture, South Valley University
}

Received on: 22-3-2021

Accepted on: 30-5-2021

\begin{abstract}
The sesame crop is considered one of the most important oil crops in Egypt, as it is well cultivated in light yellow, heavy and sandy lands that are newly reclaimed, the research aims to develop solutions to overcome the problems that hinder the increase in sesame production in Egypt. The results indicated that the average area planted with sesame was estimated at 73.73 thousand feddans during the period (2000-2018), while an average was estimated Production was estimated at 327.40 thousand ardeb, and it was found that the average total costs of the sesame crop were estimated at 2628.54 pounds, and the average total revenue was about 4762.34 pounds, while the average net per feddan revenue was estimated at 2135.76 pounds, and the farm price was estimated at 948.37 pounds, and the average profit of the spent pound was estimated. The produced ton and the ratio of revenue to costs are about $0.81,481.44$ and 1.81 pounds, respectively.

Based on the results, the research recommends the following:

1 -Developing highly productive varieties that are compatible with the Egyptian conditions, with the application of modern technology in agricultural operations, with the help of research and extension agencies.

2- Work to increase municipal fertilization and reduce the quantities of chemical fertilizers, as this leads to increased production and reduced costs.

3- Encouraging the establishment of factories concerned with industrialization in the main production areas to encourage farmers to increase their production and supply at reasonable prices .

KEYWORD: Quadratic form, Linear form, Production function, Geographical distribution of sesame , Cost function
\end{abstract}

